\title{
THE CHARACTER OF HEAT EXCHANGE IN THE ELEMENT POWERED BY RENEWABLE ENERGY
}

\author{
Ewa PIOTROWSKA, Jędrzej TRAJER, Piotr SKOWROŃSKI, \\ Dariusz CZEKALSKI \\ Department of Fundamental Engineering, Warsaw University of Life Sciences - SGGW, POLAND \\ E-mail of corresponding author: ewa_piotrowska@sggw.pl
}

Keywords: renewable energy, solar energy, heat exchanger, solar collector, sustainable agriculture

\begin{abstract}
Among other renewable resources of energy, solar energy has a small but dynamically increasing share. Solar irradiance is characterized by large variability, especially in the 24-hour cycle. Therefore, machines that use solar energy work in transient states. The character of heat exchange for the plate solar collector and the heat exchanger working in the hybrid system was investigated. The character of heat exchange turned out to be oscillatory for both machines mentioned above. The investigations of the heat exchanger model in laboratory conditions have been carried out to analyse the observed phenomenon in detail. The investigations confirmed the previously observed oscillatory character of heat exchange. As this phenomenon is unfavourable, working out methods of process control to stabilize the operation of these machines is highly recommended.
\end{abstract}

\section{INTRODUCTION}

Recently, technologies that facilitate renewable energy development have become increasingly important in global and European economy. Wysokińska (2012) presented the analysis of interdependencies between sustainable agriculture and renewable energy industry. In the coming years, the main issues related to sustainable development of global economy and its regions will be areas related to the improvement of energy efficiency, sustainable agriculture and renewable energies that facilitate rural areas development. Bartkowiak A. and Bartkowiak P. (2017), in turn, analysed the concept of sustainable agriculture in Poland, with regard to its regional specificity. Apart from an improved stock of machinery, they included in the analysis renewable resources of energy, and their growing role in sustainable agriculture development. According to GUS [Central Statistical Office of Poland] (2016) solid biofuels play a dominant though decreasing role as renewable energy resources [RER] (in $201184.89 \%$ of the total production of energy from RER, $72.22 \%$ in 2015), followed by liquid biofuels (an increase from $5.76 \%$ to $10.78 \%$ in 2015) and wind energy (an increase from $3.68 \%$ to $10.76 \%)$. Solar energy has less important though dynamically increasing share in the structure of RER $(0.17 \%$ in $2011,0.52 \%$ in 2015$)$. The structure of generation and consumption of this kind of energy is specific, as in $20151655 \mathrm{TJ}(88 \%)$ of solar energy was consumed by households, and only 230 TJ (12\%) by trade and services. For households, over 4-fold increase in consumption was noted in comparison with 2011 (388 TJ). Therefore, the knowledge of proper use of devices and machines powered by solar energy is essential. RER rarely can work as separate machines. Usually, they must be connected to other, conventional sources of energy, which is related to the problem of appropriate control of the system. An example of control techniques related to anticipation of behaviour of a hybrid system made up of solar collectors and heat pump, used for plant cultivation air-conditioning, was described by Camacho et al. (2010). The system's main source of heat includes solar collectors with the area of $151 \mathrm{~m}^{2}$, and an additional source of energy is a gas furnace with the power of $68 \mathrm{~kW}$ which is turned on, if necessary. Marshall (1999), in turn, made an attempt at defining the quality of the 
hybrid system (system model and its sensitivity to parameters changes) that consisted of solar collectors, a heat exchanger, a circulator pump and a tank. A hybrid system used in the kitchen as a source of energy for cooking meals (a cooker) using solar collectors supported by LPG was presented by Prasanna and Umanand (2011). In this system, energy is transferred by the medium. Therefore, cooperation of the two types of energy, i.e. heat and electrical energy was considered. The described system, in which solar energy is complemented by gas fuel, and is sufficient for use in the kitchen, is described for conditions of strong and long-term insolation (India). Due to large variability and much smaller intensity of solar irradiance, described by e.g. Czekalski et al. (2012), this type of a system seems much less cost-effective.

\section{MEASUREMENT STANDS AND MEASUREMENTS METHODOLOGY}

One of the biggest problems related to solar energy utilization are variations of solar irradiance, both yearly and daily (Fig. 1). Rarely, there are days with the insolation illustrated by graph a); usually, there are days with higher cloudiness illustrated by graph b) and variations of cloudiness during the 24-hour day (c and d). Such variability results in the elements powered by solar energy constantly working in transient conditions. The method of predicting solar irradiance on an inclined surface with the use of artificial neural networks was worked out by Trajer and Czekalski (2005).
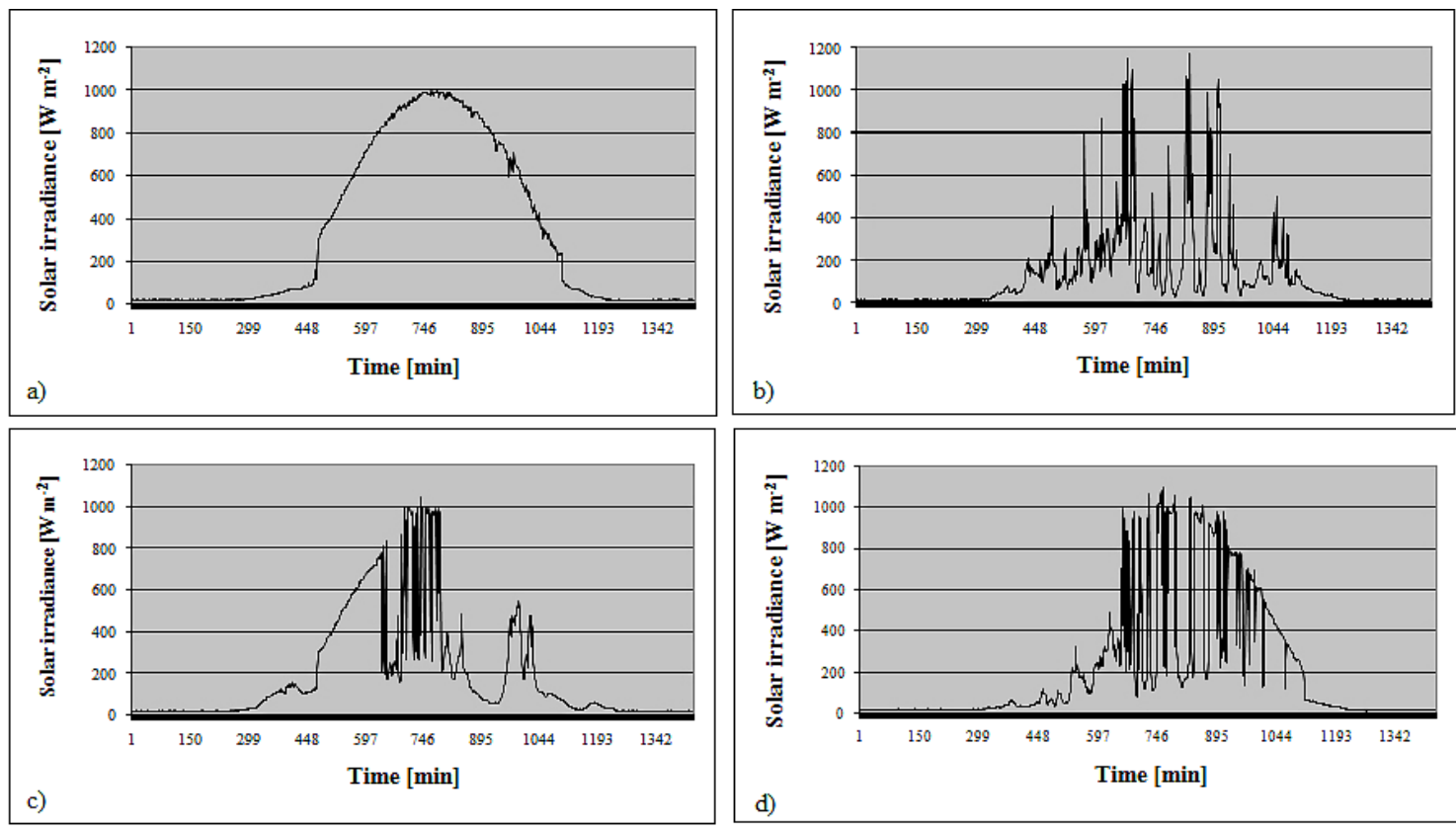

Figure 1 . The daily variability of solar irradiance for days:

a) 10.05.2011, b) 13.05.2011, c) 22.05.2011, d) 03.08.2011.

The first group of examinations was performed using the experimental set-up 1 of the hybrid power system. Figure 2 presents a part of the system that comprises flat collectors, one of the tanks and heat exchanger. For the purpose of this study, measurements of the temperatures at the input to and at the output from the collector a) and from the exchanger b) will be used. Temperature measurements are taken every minute by thermometers PT 1000. The plate exchanger being analysed is the exchanger CB26 manufactured by Alfa Laval (soldered, 18 plates). The maximum heat power is $24 \mathrm{~kW}$, and heat exchange surface area is $0.45 \mathrm{~m}^{2}$. The flow in the exchanger is 
variable, regulated by the delivery rate of the pump. On the primary side, the working medium is a mixture of water and glycol, and on the secondary side - water. The exchanger works in counter-current arrangement. The absorber of the solar collector Heliostar 200 has a total surface area of $34.6 \mathrm{~m}^{2}$. Solar irradiance measurements were performed using pyranometer CM3 with the time constant of $18 \mathrm{~s}$ and the error of \pm 25 $\mathrm{Wm}^{-2}$ at irradiance of $1000 \mathrm{Wm}^{-2}$.

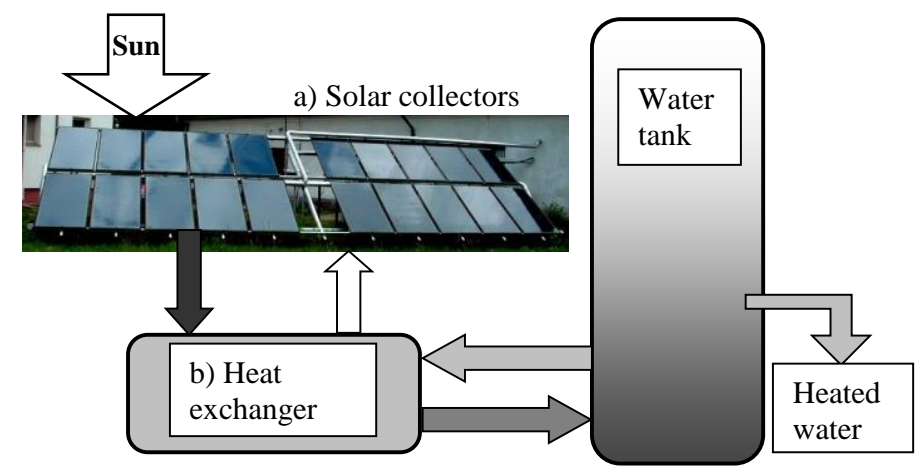

Figure 2. Fragment of the hybrid system in Budy Grabskie, measurement stand 1

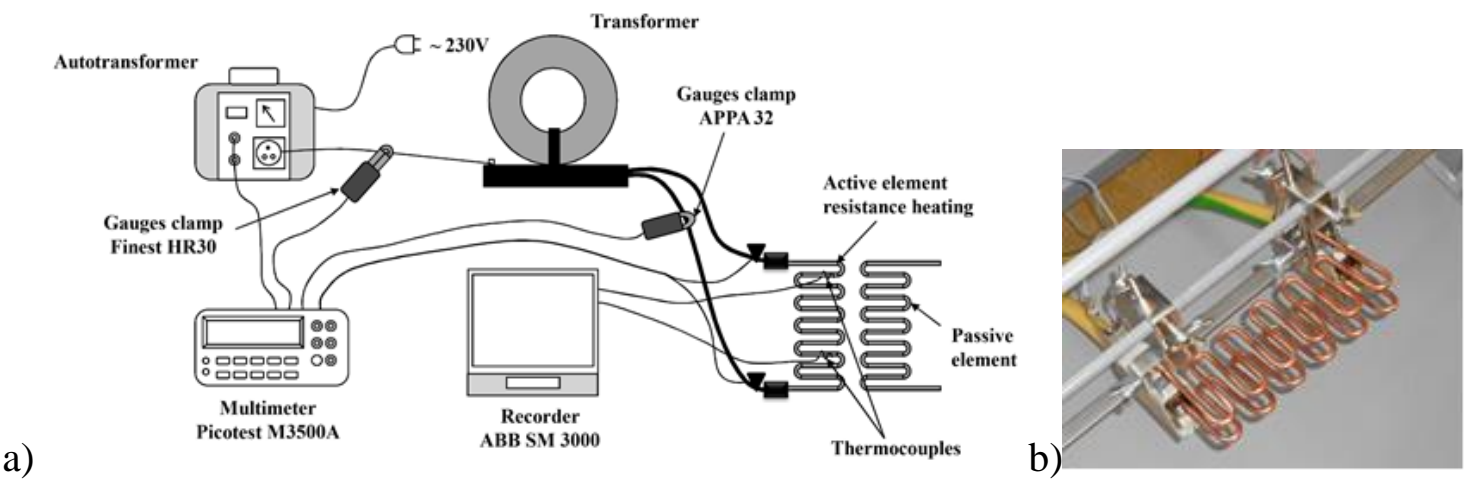

Figure 3. a) Diagram of the measurement stand 2 of the heat exchanger model, b) the positional relationship between the elements.

Another set of tests was performed at measurement stand 2, presented in figure 3 . The heat exchanger is modelled by two elements: active, transferring heat and passive collecting heat. The elements were made of copper rod with $\phi=5 \mathrm{~mm}$. The active element was resistance heated, with air being the heating medium. Temperatures were measured every second in 6 points on both elements using coated K-type thermocouples (insulated, $0.5 \mathrm{~mm}$ tip). Screen Master 3000 recorder manufactured by ABB was used to record and archive the results. The maximum measurement error for thermocouples in the temperature range was $\pm 1.5^{\circ} \mathrm{C}$, and the maximum error of the recorder $\pm 0.01 \%$.

\section{ANALYSIS OF RESULTS AND DISCUSSION}

The results obtained in stand 1 were divided into two groups. The first group showed the variability of temperature obtained in the solar collector as a function of solar irradiance, and the second - variability of temperature at the output from the heat exchanger versus temperature at the input to the exchanger. Measurements, at measurement stand 2 involved only heat exchanger model, and were performed in order to determine the dependence of the temperature of the passive element (modelling the secondary side of the exchanger) on the temperature of the active element (modelling 
the primary side of the exchanger). MATLAB with the System Identification Toolbox library was used to analyse all the obtained results. The necessity to precisely define the dependencies between the input and output values of the objects being studied required signal analysis allowing for investigation of the character of the element based on its STEP characteristics.

a)

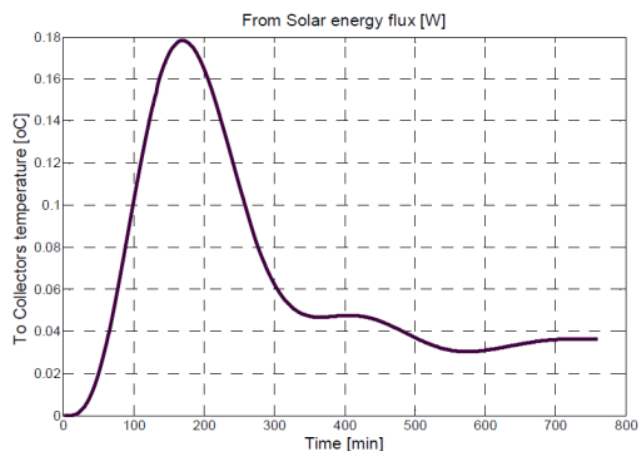

b)

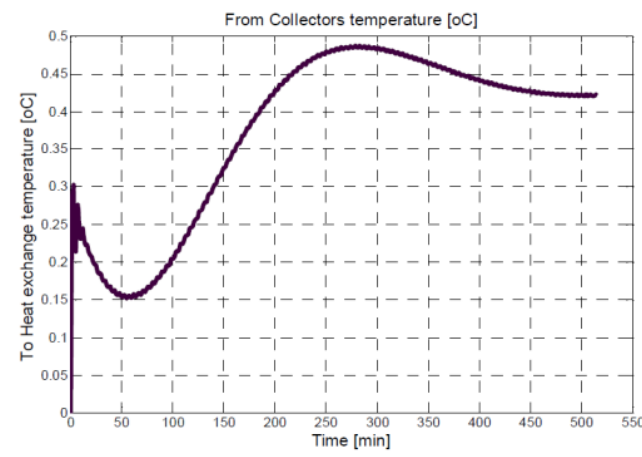

Figure 4. The STEP characteristics for:

a) solar collector (input: heat flux from solar energy, output: collectors output temperature),

b) heat exchanger (input: heat exchanger input temperature, output: heat exchanger output temperature)

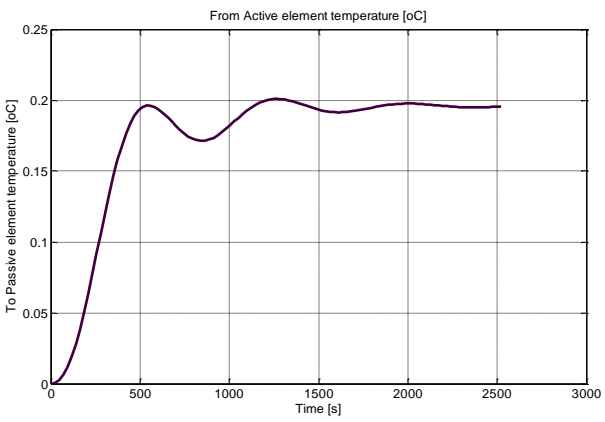

Figure 5. STEP characteristic for heat exchanger model

(input: active element temperature, output: passive element temperature)

Figure 4 presents STEP characteristics for a) solar collector and b) heat exchanger examined during the day with solar irradiance represented by figure $1 \mathrm{~d}$. In both cases, oscillatory character of the investigated heat exchange was observed. For more precise determination of the degree of dependence of the observed character of unstable variability of irradiance observed in figured $1 \mathrm{~d}$, further examinations of heat exchanger model presented in figure $3 \mathrm{~b}$ were performed. The resistance heated active element showed a stable rise in the temperature, to a greater extent corresponding to irradiance variability observed in figure $1 \mathrm{a}$, and rarely occurring in reality. However, it proved that the analysis of the obtained results also revealed oscillatory character of the element being examined, with the STEP response of the element being presented in Fig. 5.

Oscillations in heat phenomena were also observed by other researchers. Problems of dynamic regulation of temperature was also studied by Wesołowski et al. (2011), indicating oscillations of temperature of the heating element for step change of the setpoint temperature of the input function. Oscillations of temperature in transient states were also observed by Zerihun Desta et al. (2005) studying the course of heat exchange during the ventilation of a room. Espinosa-Paredes and Espinosa-Martinez (2009), Valle-Hernandez et al. (2011) and Espinosa-Paredes et al. (2011) wrote a series of 
papers related to their many years' research and experiments. The authors analysed a nuclear reactor of BWR type (Boling Water Reactor). The analysis of processes occurring in the reactor led to the description of this reactor model by Espinosa-Paredes and Espinosa-Martinez (2009), and development of the equivalent electrical diagram, using thermo-electrical analogy by Valle-Hernandez et al. (2011). In this diagram, heat inductance occurs, which corresponds to the oscillations observed by Espinosa-Paredes and Espinosa-Martinez (2009). Oscillations of temperature were also observed during examinations of the plate heat exchanger dynamics by Obstawski (2012). Oscillations were also observed by Piotrowska and Chochowski (2012) for various types of exchangers, namely plate as well as shell and tube heat exchangers. Oscillations are an unfavourable phenomenon. Therefore, finding methods to counteract their occurrence is recommended. Such attempts were made by Díaz et al. (2001) by using a neural network to control the heat exchanger and for the purpose of elimination of oscillations, observed in transient states. Similar attempts, based on using neural networks for control of dynamic courses of heat exchange were made by Fichera and Pagano (2002), with consideration to their oscillatory character as well as Varshney and Panigrahi (2005), who described using a neural network for controlling heat exchanger.

\section{CONCLUSIONS}

There is a strong relation between sustainable farming and renewable sources of energy. At present, use of solar energy in Poland is small in comparison with other sources of energy, especially biofuels, but it shows a growing tendency, and its share in total renewable energy is increasing. The value of solar irradiance changes in a very dynamic and unpredictable way, with large variations being related not only to the season of the year or the time of the day but also to the current value of cloudiness. The devices that use solar energy work in conditions of large variability of input stream of heat. Transient states result in the changes of the character of their work. Oscillations of temperature were observed in the examined solar collectors combined with the heat exchanger. In order to assess whether the observed oscillations also occur for other values of parameters of heat exchange and their variability, investigations in laboratory conditions for the heat exchanger model were performed. The analysis of results of these investigations confirmed the occurrence of oscillations. Since they are unfavourable to devices in operation, it is recommended to work out models allowing to control the course of heat exchange and taking appropriate actions to avoid oscillations. These tasks may be realized with the help of e.g. neural networks.

\section{REFERENCES}

Bartkowiak, A., Bartkowiak, P. (2017). Technical and technological progress in the context of sustainable development of agriculture in Poland. Procedia Engineering, 182, 66-75.

Camacho, E.F.,Ramirez, D.R., Limon, D., Muñoz de la Peña, D., Alamo, T. (2010). Model predictive control techniques for hybrid systems. Annual Reviews in Control, 34, 21-31.

Czekalski, D., Chochowski, A., Obstawski, P. (2012). Parametrization of daily solar irradiance variability. Renewable and Sustainable Energy Reviews, 16, 2461-2467.

Díaz, G., Sen, M., Yang, K.T., McClain, R.L. (2001). Dynamic prediction and control of heat exchangers using artificial neural networks. International Journal of Heat and Mass Transfer, 44, 1671-1679.

Espinosa-Paredes, G., Espinosa-Martinez, E.-G. (2009). Fuel rod model based on Non-Fourier heat conduction equation. Annals of Nuclear Energy, 36, 680-693. 
Espinosa-Paredes, G., Polo-Labarrios, M.-A., Espinosa-Martinez, E.-G., Valle-Gallegos, E. (2011). Fractional neutron point kinetics equations for nuclear reactor dynamics. Annals of Nuclear Energy, 38, 307-330.

Fichera, A., Pagano, A. (2002). Neural network-based prediction of the oscillating behavior of a closed loop thermosyphon. International Journal of Heat and Mass Transfer, 45, 3875-3884.

GUS (Central Statistical Office). (2016). Energy from renewable sources in 2015. Warsaw, 31-34, 54.

Marshall, R. (1999). A generalized steady state collector model including pipe losses, heat exchangers and pump powers. Solar Energy, 66 (6), 469-477.

Obstawski, P. (2012). Modelowanie dynamiki pracy płytowego wymiennika ciepła w układzie przeciwprądowym. Przegląd Elektrotechniczny, 88 (3a), 156-160.

Piotrowska, E., Chochowski, A. (2012). Application of parametric identification methods for the analysis of the heat exchanger dynamics. International Journal of Heat and Mass Transfer, 55, 7109-7118.

Prasanna, U.R., Umanand, L. (2011). Modeling and design of a solar thermal system for hybrid cooking application. Applied Energy, 88, 1740-1755.

Trajer, J., Czekalski, D. (2005). Prognozowanie sum napromieniowania słonecznego dla potrzeb energetyki słonecznej. Inżynieria Rolnicza 68 (8), 393-399.

Valle-Hernández, J., Espinosa-Paredes, G., Morales-Sandoval, J. B. (2011). Identification of an equivalent electrical model to a natural circulation BWR core model. Annals of Nuclear Energy, 38, 2848-2858.

Varshney, K., Panigrahi, P.K. (2005). Artificial neural network control of a heat exchanger in a closed flow air circuit. Applied Soft Computing, 5, 441-465.

Wesołowski, M., Niedbała, R., Kucharski, D., Czaplicki, A. (2011). Problematyka dynamicznej regulacji temperatury w nieliniowych obiektach elektrotermicznych. Przegląd Elektrotechniczny, 87 (7), 1-5.

Wysokińska, Z. (2012). Mutual dependence between sustainable energy- and sustainable agriculture policies-from the global and European perspective, Comparative Economic Research, 15 (3), 5-22.

Zehirun Desta, T., Van Brecht, A., Quanten, S., Van Buggenhhout, S., Meyers, J., Baelmans, M., Berckmans, D. (2005). Modelling and control of heat transfer phenomena inside a ventilated air space. Energy and Buildings, 37, 777-786. 